\title{
Effect of recombinant human granulocyte colony-stimulating factor on T-lymphocyte function and the mechanism of this effect
}

\author{
Song-He Chen $\cdot$ Xin $\mathrm{Li} \cdot$ Xiao-Jun Huang
}

Published online: 14 May 2009

(C) The Japanese Society of Hematology 2009

\section{Erratum to: Int J Hematol (2004) 79:178-184 \\ DOI 10.1532/IJH97.A10227}

There are errors in Tables 1 and 2. The correct versions are given below.

Table 1 Alteration of T-cell subsets and monocytes after in vivo recombinant human granulocyte colony-stimulating factor (G-CSF) administration $(n=21)$

\begin{tabular}{lccc}
\hline \multicolumn{4}{c}{ T-cell subsets } \\
\cline { 2 - 4 } & $\begin{array}{l}\text { Pre-G-CSF } \\
\left(\times 10^{9} / \mathrm{L}\right)\end{array}$ & $\begin{array}{c}72 \text { h Post-G- } \\
\text { CSF }\left(\times 10^{9} / \mathrm{L}\right)\end{array}$ & $\begin{array}{l}\text { 96 h Post-G- } \\
\text { CSF }\left(\times 10^{9} / \mathrm{L}\right)\end{array}$ \\
\hline $\mathrm{CD}^{+}$ & $1.21 \pm 0.40$ & $2.09 \pm 0.56^{\dagger}$ & $1.80 \pm 0.45^{\dagger}$ \\
$\mathrm{CD}^{+} \mathrm{CD} 4^{-} \mathrm{CD} 8^{-}$ & $0.042 \pm 0.029$ & $0.198 \pm 0.107^{\dagger}$ & $0.139 \pm 0.093^{\dagger}$ \\
$\mathrm{CD}^{+} 4^{+}(n=30)$ & $0.34 \pm 0.12$ & $1.18 \pm 0.52^{\dagger}$ & $1.60 \pm 0.86^{\dagger}$ \\
\hline
\end{tabular}

Data are presented as mean $\pm \mathrm{SE}$

${ }^{\dagger} P<0.05$, post-G-CSF versus pre-G-CSF

The online version of the original article can be found under doi:10.1532/IJH97.A10227.

S.-H. Chen $\cdot$ X. Li $\cdot$ X.-J. Huang $(\bowtie)$

Peking University Institute of Hematology,

Peking University People's Hospital,

100044 Beijing, People's Republic of China

e-mail: xjhrm@medmail.com.cn
Table 2 Proliferation changes after in vivo recombinant human granulocyte colony-stimulating factor (G-CSF) administration $(n=21)$

\begin{tabular}{|c|c|c|c|}
\hline & \multicolumn{3}{|l|}{ T-cell subsets } \\
\hline & $\begin{array}{l}\text { Pre-G-CSF } \\
(\%)\end{array}$ & $\begin{array}{l}72 \text { h Post- } \\
\text { G-CSF }(\%)\end{array}$ & $\begin{array}{l}96 \text { h Post- } \\
\text { G-CSF }(\%)\end{array}$ \\
\hline $\begin{array}{l}\text { Leukopheresis } \\
\text { product }\end{array}$ & $238.03 \pm 58.74$ & $167.65 \pm 48.46^{\dagger}$ & $127.36 \pm 37.96^{\dagger, *}$ \\
\hline $\begin{array}{l}\text { Peripheral } \\
\text { blood }\end{array}$ & & $134.85 \pm 45.68^{\dagger}$ & $124.63 \pm 34.88^{\dagger}$ \\
\hline $\begin{array}{l}\text { Data are presen } \\
{ }^{\dagger} P<0.05, \text { pos } \\
+P<0.05,96\end{array}$ & $\begin{array}{l}\text { nted as mean } \pm S \\
\text { ost-G-CSF versus } \\
6 \text { post-G-CSF ve }\end{array}$ & $\begin{array}{l}\text { pre-G-CSF } \\
\text { ersus } 72 \mathrm{~h} \text { post-G- }\end{array}$ & $-\mathrm{CSF}$ \\
\hline
\end{tabular}

